\title{
ATIVIDADE ANTIMICROBIANA DE BIOFILME COM ÓLEOS ESSENCIAIS PARA CONSERVAÇÃO PÓS-COLHEITA DE TOMATE CV RASTEIRO
}

\section{ANTIMICROBIAL ACTIVITY OF BIOFILM WITH ESSENTIAL OILS FOR THE CONSERVATION AFTER HARVEST OF TOMATO CV RASTEIRO}

\author{
Fernanda Rita ${ }^{1}$; Luciane Bernardo Salles ${ }^{2}$; Raíssa Arantes Barboza ${ }^{3}$; Maria Carolina de Oliveira ${ }^{4}$; \\ Rosilene Aparecida Prestes ${ }^{5}$; Denise Milléo Almeida ${ }^{6}$ \\ ${ }_{1,2,3,4,5,6}$ Universidade Tecnológica Federal do Paraná - UTFPR - Ponta Grossa - Brasil \\ ferbruxinha@hotmail.com
}

\begin{abstract}
Resumo
O objetivo deste trabalho foi avaliar a aplicação de biofilme com óleos essenciais, com atividade antimicrobiana, para conservação pós-colheita de tomate cv Rasteiro. Os tomates foram cobertos com biofilme, tendo como composição fécula de batata e glicerol, nas proporções de 2,5\% e 0,7\%, respectivamente, e a adição de $0,5 \%$ dos óleos essenciais sálvia e manjerona, segundo planejamento experimental fatorial $2^{2}$, armazenados em temperatura ambiente durante $288 \mathrm{~h}$. Os tomates com biofilme adicionado de óleos essenciais apresentaram contagem microbiana dentro do limite aceitável de $10^{6} \mathrm{UFC} / \mathrm{g}$ até 168 horas. A atividade de água não apresentou variação significativa durante o período de armazenamento. Todos os tratamentos (1, 2, 3, 4 e 5) tiveram aumentos de 94,0\%, 108,6\%, 126,3\%, 37,1\% e 107,0\%, respectivamente, nos valores dos compostos fenólicos totais até 216h. Os tomates cobertos com biofilmes com adição da combinação de sálvia e manjerona mostraram maior eficiência na atividade antimicrobiana, e na manutenção da concentração dos compostos fenólicos, promovendo aumento da vida de prateleira ao serem armazenados em temperatura ambiente.
\end{abstract}

Palavras-chave: biofilme, óleos essenciais, tomate, atividade antimicrobiana.

\section{Introdução}

O tomate apresenta-se entre as hortaliças mais comercializadas e o Brasil é o oitavo maior produtor com produção superior a três milhões de toneladas de fruto ao ano. Entretanto, $21 \%$ desta produção sofrem danos que dificultam a sua comercialização, consequência de técnicas inadequadas em todas as etapas do processo, desde o campo ate o consumidor final (BOLZAN, 2008). Perdas significativas são verificadas na pós-colheita, ocasionadas por injurias mecânicas, armazenamento e transporte inadequado, e ampla exposição no varejo, sendo porta de entrada para a contaminação por fungos e bactérias (CHITARRA e CHITARRA, 2005). 
Atualmente, as principais formas empregadas para manter a qualidade de frutas e hortaliças estão relacionadas ao uso de embalagens poliméricas, manutenção em ambientes refrigerados, emprego de sanitizantes e aplicação de atmosfera modificada e técnicas de irradiação (BENDER et al., 2010). No entanto, ainda há significativas perdas de qualidade, pois as estratégias e técnicas de manutenção não tem sido suficiente para o processo de preservação.

Biofilmes produzidos a partir de polímeros naturais não tóxicos têm se firmado como uma nova categoria de materiais de alto potencial, para aplicação como revestimentos protetores comestíveis sobre frutos e legumes (ASSIS et al., 2008). A adição de antimicrobianos naturais (bioconservantes) como óleos essenciais, na formulação dos biofilmes, visa garantir um alimento seguro e manter inalterada a qualidade do produto, devido sua origem natural e redução da resistência microbiana causado pelos componentes químicos antimicrobianos que fazem parte dos óleos essenciais. A atividade antimicrobiana de óleos essenciais está vinculado à alteração da permeabilidade e integridade da membrana celular bacteriana (LAMBERT et al., 2001) e também relacionada ao teor de compostos fenólicos (DAVIDSON e NAIDU, 2000).

A salvia, Salvia officinalis, é conhecida por suas propriedades anti-sépticas, cicatrizante, bactericida e antioxidante e a majerona pela capacidade antioxidante e bactericida, sendo eficaz contra Bacillus subtilis, Clostridium botulinium, Escherichia coli, Listeria monocytogenes, Salmonella tyhimurium, Staphylococcus aureus (FOOD INGREDIENTS BRASIL, 2010). Existem várias plantas com atividade antimicrobiana e os óleos essenciais produzidos a partir destas potencializam a ação antimicrobiana. Desta forma, é necessário estudar novos agentes que possam auxiliar a substituição racional dos conservantes químicos comumente utilizados no controle microbiano e possibilitar sua inclusão nos métodos de conservação de alimentos. (BEUCHAT e GOLDEN, 1989).

O objetivo deste trabalho foi avaliar a aplicação de biofilme com óleos essenciais, com atividade antimicrobiana, para conservação pós-colheita de tomate cv Rasteiro.

\section{Material e Métodos}

\section{Material}

Tomate (Solanum lycopersicum) da variedade 'Rasteiro', fécula de batata (Yoki), glicerol PA (Merck), óleos essenciais de salvia (Salvia officinalis) (Givaldan) e manjerona (Origanum majorana L) (Givaldan) foram os principais materiais utilizados neste trabalho. 


\section{Métodos}

\section{Produção do biofilme}

A produção do biofilme teve como composição básica fécula de batata e glicerol, nas proporções de 2,5\% e 0,7\%, respectivamente (Almeida, 2010) e a adição de 0,5\% dos óleos essenciais sálvia e manjerona, que foram aplicados segundo planejamento experimental fatorial $2^{2}$, conforme tabela 1. As soluções filmogênicas foram produzidas por meio da técnica de mistura, e aquecidas à $70^{\circ} \mathrm{C}$, sob agitação de 50 rotação por minuto (rpm), durante 25 minutos. Após resfriamento, em temperatura ambiente, foram adicionados os óleos essenciais.

Tabela 1 - Planejamento experimental fatorial $2^{2}$

\begin{tabular}{|c|c|c|c|c|c|}
\hline \multirow[b]{2}{*}{ Ensaios } & \multicolumn{2}{|c|}{ Variáveis independentes } & \multicolumn{3}{|c|}{$\begin{array}{ll}\text { Variáveis dependentes } \\
\end{array}$} \\
\hline & Salvia & Manjerona & $\begin{array}{c}\text { Mesófilos Aeróbios } \\
\text { Totais }\end{array}$ & $\begin{array}{c}\text { Atividade de } \\
\text { água }\end{array}$ & $\begin{array}{c}\text { Compostos } \\
\text { Fenólicos Totais }\end{array}$ \\
\hline 1 & -1 & -1 & & & \\
\hline 2 & +1 & -1 & & & \\
\hline 3 & -1 & +1 & & & \\
\hline 4 & +1 & +1 & & & \\
\hline 5 & \multicolumn{2}{|c|}{ Controle sem biofilme } & & & \\
\hline
\end{tabular}

\section{Processamento mínimo dos frutos e revestimento}

Foram adquiridos 150 tomates com grau de maturação verde-maduro e conduzidos a lavagem e a sanitização, com 150 ppm hipoclorito de sódio por 15 minutos. Seguido de enxágüe e secagem sob ventilação forçada de ar por 1 hora (Arno), em temperatura ambiente

Os frutos sanitizados e secos foram imersos em soluções filmogênicas até a completa cobertura e colocados sobre grades, sob ventilação forçada de ar por 90 minutos (Arno), para acelerar o processo secagem e de cura (polimerização) do filme. Após secos, foram distribuídos em bandejas de poliestireno $(150 \times 150 \times 18 \mathrm{~mm})$ e mantidos em temperatura ambiente, entre $18^{\circ} \mathrm{C}$ a $23^{\circ} \mathrm{C}$, por 288 horas.

\section{Avaliação da eficiência do biofilme nos frutos}

Os indicadores de qualidade analisados para a avaliação da eficiência da atividade antimicrobiana dos biofilmes no fruto foram contagem de mesófilos aeróbios totais, atividade de água (aw) e compostos fenólicos. As análises foram realizadas em triplicata, nos tempos 0h, 72h, $168 \mathrm{~h}, 216 \mathrm{~h}$ e $288 \mathrm{~h}$. Os tomates foram avaliados em relação à carga microbiana, pela contagem total de mesófilos aeróbios segundo SILVA et al. (2010). A Atividade de água foi determinada com higrômetro AQUA Lab (série 3TE) com sensor de infravermelho, com precisão de $\pm 0,003$, em temperatura ambiente de $20^{\circ} \mathrm{C} \pm 0,1^{\circ} \mathrm{C} . \mathrm{O}$ teor de compostos fenólicos totais foram quantificados 
usando o método de Folin-Ciocalteau (Singleton e Rossi, 1965). Foi utilizado catequina como padrão (200 mg. $\left.\mathrm{L}^{-1}\right)$. Os resultados expressos em mg. $\mathrm{L}^{-1}$ de catequina.

\section{Análise dos dados}

Os dados obtidos foram submetidos à análise de variância (ANOVA). Para verificar quais tratamentos diferiram, foi aplicado o teste de Tukey para realizar comparações pareadas das médias dos tratamentos estabelecendo-se o nível mínimo de significância de 5\% ( $\leq \leq 0,05)$, utilizando o programa Statistica versão 5.0.

\section{Resultados e Discussão}

\section{Contagem de Mesófilos Aeróbios Totais}

A Agência Nacional de Vigilância Sanitária (ANVISA) não estabelece limites quanto à contagem de mesófilos aeróbios totais para produtos minimamente processados. No entanto, o crescimento excessivo destes contaminantes compromete a aparência, o sabor e o aroma do produto, provocando uma redução na aceitação sensorial. A carga microbiana de $10^{6}$ unidades formadora de colônia por grama de produto $\left(\mathrm{UFC} \cdot \mathrm{g}^{-1}\right.$ ) foi estabelecida como população limite aceitável, já que em populações superiores a esta, substâncias tóxicas podem ser produzidas (VIEITES et al., 2004).

As diferentes concentrações dos óleos nos biofilmes promoveram alterações significativas $(\mathrm{p} \leq 0,05)$ na contagem de mesófilos aeróbios totais, entre os tratamentos. Porém durante o período de armazenamento não houve diferenças significativas, confirmada pelo teste de Tukey (Tabela 2).

Tabela 2 - Características da contagem de Mesófilos Aeróbios Totais em Tomate cv Rasteiro coberto com biofilme de diferentes concentrações de óleo essenciais, durante o período de armazenamento

\begin{tabular}{|c|c|c|c|c|c|c|c|}
\hline$\cdot \frac{\infty}{\pi}$ & Tempo & & & ratamento & & & Média \\
\hline$\stackrel{0}{\ominus}$ & & 1 & 2 & 3 & 4 & 5 & \\
\hline$\stackrel{0}{\frac{0}{3}}$ & 0 & $3,3 \times 10^{3 a}$ & $1,2 \times 10^{3 a}$ & $5,5 \times 10^{3 a}$ & $3,1 \times 10^{3 a}$ & $1,1 \times 10^{3 a}$ & $2,8 \times 10^{3 \mathrm{C}}$ \\
\hline : & & $26,7 \%$ & $28,8 \%$ & $48,4 \%$ & $84,0 \%$ & $15,7 \%$ & \\
\hline$\sum_{1}$ & 72 & $2,5 \times 10^{4 a}$ & $4,3 \times 10^{3 \mathrm{~b}}$ & $4,1 \times 10^{3 \mathrm{~b}}$ & $3,3 \times 10^{2 b}$ & $2,6 \times 10^{4 a}$ & $1,2 \times 10^{4 \mathrm{C}}$ \\
\hline : & & $0 \%$ & $64,3 \%$ & $34,6 \%$ & $62,4 \%$ & $57,2 \%$ & \\
\hline 过 & 168 & $1,6 \times 10^{6 a}$ & $6,4 \times 10^{5 \mathrm{ab}}$ & $1,1 \times 10^{4 b}$ & $3,1 \times 10^{2 b}$ & $1,7 \times 10^{6 a}$ & $8,0 \times 10^{5 \mathrm{BC}}$ \\
\hline$\stackrel{\infty}{2} 已$ & & $28,9 \%$ & $62,9 \%$ & $16,4 \%$ & $35,1 \%$ & $73,2 \%$ & \\
\hline$\sum$ & 216 & $3,2 \times 10^{6 a}$ & $1,7 \times 10^{6 a b}$ & $6,8 \times 10^{5 \mathrm{ab}}$ & $2,3 \times 10^{3 \mathrm{~b}}$ & $3,3 \times 10^{6 a}$ & $1,7 \times 10^{6 \mathrm{~A}}$ \\
\hline ت & & $14,4 \%$ & $35,2 \%$ & $28,9 \%$ & $44,1 \%$ & $73,7 \%$ & \\
\hline हี & 288 & $1,7 \times 10^{6 \mathrm{~b}}$ & $1,1 \times 10^{6 b}$ & $2,5 \times 10^{6 \mathrm{ab}}$ & $2,0 \times 10^{4 b}$ & $3,9 \times 10^{6 a}$ & $1,8 \times 10^{6 \mathrm{AB}}$ \\
\hline$\underset{\Xi}{=}$ & & $25,6 \%$ & $13,8 \%$ & $2,2 \%$ & $39,7 \%$ & $29,5 \%$ & \\
\hline ē & Média & $7,8 \times 10^{\mathrm{ab}}$ & $4,9 \times 10^{b c}$ & $2,4 \times 10^{b c}$ & $1 \times 10^{4 \mathrm{C}}$ & $5.4 \times 10^{\mathrm{a}}$ & \\
\hline
\end{tabular}


Os tratamentos com biofilme adicionado de óleos essenciais apresentaram contagem microbiana dentro do limite aceitável de $10^{6}$ UFC/g (VIEITES et al., 2004), até 168 horas, o que não ocorreu com o tratamento 1 e 5, ultrapassando o limite neste período (Figura 1).

Figura 1 - Evolução da contagem de mesófilos aeróbios totais em tomate cv. Rasteiro coberto com biofilme de diferentes concentrações de óleo essenciais, durante o período de armazenamento

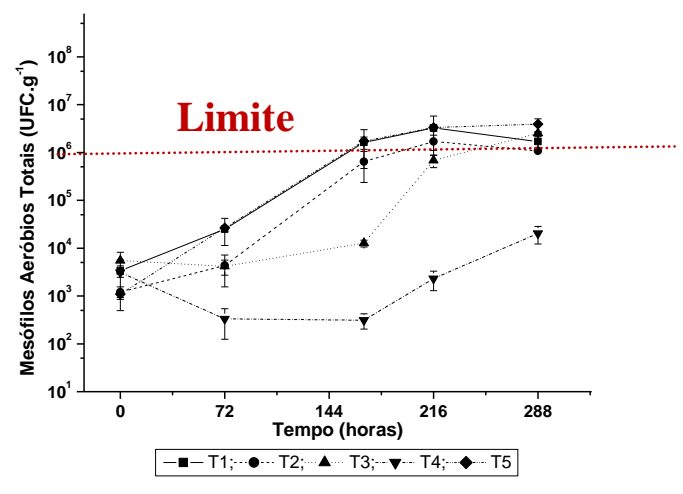

A utilização dos óleos essenciais na composição dos biofilmes promoveu inibição ao desenvolvimento microbiano. A salvia, Salvia officinalis, apresenta como principais componentes antimicrobianos o canfrol 6 a 15\%, $\alpha$ pineno 4 a 5\%, $\beta$ pineno 2 a 10\%, 1,8 cineol 2 a 14\%, $\alpha$ tujona 20 a 42\% (Burt, 2004 apud Souza, 2006) e a manjerona apresenta o 4-terpineol e o cissabineno como substâncias química majoritárias no seu óleo essencial, também responsáveis pelo sabor, odor e a atividade antimicrobianas.

Segundo Food Ingredients Brasil (2010) a salvia e a manjerona apresentam ação antimicrobiana para os microrganismos Bacillus subtilis, Clostridium botulinium, Escherichia coli, Listeria monocytogenes, Salmonella tyhimurium, Staphylococcus e aureus. Em trabalho desenvolvido por Pereira et al. (2004) a adição de óleo essencial de Salvia officinalis em culturas microbianas apresentou importante atividade antimicrobiana, com eficácia de $100 \%$ sobre espécies de Enterobacter e Klebsiella, 96\% sobre Escherichia coli, 83\% para Proteus mirabilis e 75\% sobre Morganella morganii. Singh et al. (2003) verificaram a ação antimicrobiana dos óleos essenciais da pimenta, tomilho, salvia, cravo e alecrim no desenvolvimento de Listeria monocytogenes em sistema in vitro como em produtos alimentícios, e constataram maior eficiência na análise in vitro. Busatta et al. (2008) analisaram a atividade antimicrobiana do óleo essencial de O. majorana em lingüiça e mostraram que o óleo essencial de manjerona teve efeito bacteriostático em baixas concentrações e bactericidas em maiores concentrações de óleo, o que provocou alterações no sabor.

O uso de películas comestíveis de baixa permeabilidade a gases, como é o caso de polissacarídios, reduz o acesso do oxigênio aos tecidos, minimizando as alterações causadas pela deterioração de microrganismos em frutas processadas (Kester e Fennema, 1986), o que sugere ter 
auxiliado na baixa concentração de mesófilos aeróbios totais comparado com o tratamento 5 (controle). Entretanto, a evolução da atividade de água, entre os tratamentos, não auxiliou a redução no desenvolvimento microbiano, confirmado pelos altos valores encontrados durante o período de armazenamento (Tabela 3).

\section{Atividade de água}

A atividade de água (Aw) não foi influenciada estatisticamente pelos resultados das médias dos parâmetros, tratamentos e tempos de armazenamento, ao nível de confiança de $95 \%(\mathrm{p}>0,05)$, confirmada pelo teste de Tukey (Tabela 3).

Tabela 3 - Características da atividade de água em Tomate cv Rasteiro coberto com biofilme de diferentes concentrações de óleo essenciais, durante o período de armazenamento

\begin{tabular}{|c|c|c|c|c|c|c|c|}
\hline \multirow{8}{*}{ 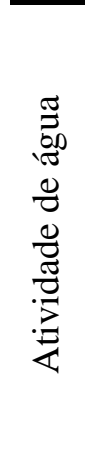 } & \multirow{2}{*}{$\begin{array}{l}\text { Tempo } \\
\text { (horas) }\end{array}$} & \multicolumn{5}{|c|}{ Tratamentos } & \multirow[b]{2}{*}{ Média } \\
\hline & & $\mathbf{1}$ & 2 & $\mathbf{3}$ & 4 & 5 & \\
\hline & 0 & $0,9899^{\mathrm{a}} \pm 0,0$ & $0,9884^{\mathrm{a}} \pm 0,0$ & $0,9893^{\mathrm{a}} \pm 0,0$ & $0,9878^{\mathrm{a}} \pm 0,0$ & $0,9978^{\mathrm{a}} \pm 0,0$ & $0,9872^{\mathrm{A}}$ \\
\hline & 72 & $0,9925^{\mathrm{a}} \pm 0,0$ & $0,9901^{\mathrm{a}} \pm 0,0$ & $0,9866^{\mathrm{a}} \pm 0,0$ & $0,9853^{\mathrm{a}} \pm 0,0$ & $0,9846^{\mathrm{a}} \pm 0,0$ & $0,9893^{\mathrm{A}}$ \\
\hline & 168 & $0,9891^{\mathrm{a}} \pm 0,0$ & $0,9884^{\mathrm{a}} \pm 0,0$ & $0,9912^{\mathrm{a}} \pm 0,0$ & $0,9880^{\mathrm{a}} \pm 0,0$ & $0,9969^{\mathrm{a}} \pm 0,0$ & $0,9894^{\mathrm{A}}$ \\
\hline & 216 & $0,9732^{\mathrm{a}} \pm 0,0$ & $0,9976^{\mathrm{a}} \pm 0,0$ & $0,9842^{\mathrm{a}} \pm 0,0$ & $0,9845^{\mathrm{a}} \pm 0,0$ & $0,9953^{\mathrm{a}} \pm 0,0$ & $0,9767^{\mathrm{A}}$ \\
\hline & 288 & $0,9921^{\mathrm{a}} \pm 0,0$ & $0,9870^{\mathrm{a}} \pm 0,0$ & $0,9901^{\mathrm{a}} \pm 0,0$ & $0,9986^{\mathrm{a}} \pm 0,0$ & $0,9982^{\mathrm{a}} \pm 0,0$ & $0,9905^{\mathrm{A}}$ \\
\hline & Média & $0,9810^{\mathrm{a}}$ & $0,9890^{\mathrm{a}}$ & $0,9894^{\mathrm{a}}$ & $0,9871^{\mathrm{a}}$ & $0,9865^{\mathrm{a}}$ & \\
\hline
\end{tabular}

NOTA - Valores com letras minúsculas iguais na linha não diferem pelo teste de Tukey ( $\leq 00,05)$, em nível de $95 \%$ confiança; e valores com letras maiúsculas iguais na coluna não diferem pelo teste de Tukey $(\mathrm{p} \leq 0,05)$, em nível de confiança de $95 \%$. São apresentados os valores médios das triplicatas de cada tempo e respectivo desvio padrão.

A oscilação não foi significativa, porém pode estar relacionada à temperatura de estocagem entre $18^{\circ} \mathrm{C}$ a $20^{\circ} \mathrm{C}$, e com a redução da pressão parcial de vapor de água formada sobre a superfície dos frutos pela aplicação do biofilme. O tratamento 4 apresentou aumento de 1,04\% na atividade de água durante o período de armazenamento, enquanto os tratamentos 1, 3 e 5 os aumentos foram de $0,22 \%, 0,08 \%$ e $0,04 \%$, respectivamente. Somente o tratamento 2 apresentou redução de $0,14 \%$ na atividade de água. $\mathrm{O}$ aumento na atividade de água pode ser atribuído a umidade relativa ao ambiente de armazenamento em torno de 85\%. A variação da Aw inicial de 0,98 a 0,99 entre os tratamentos podem ser decorrente do processo de sanitização e da aplicação da solução filmogênica nesses tratamentos (Tabela 1). A adição de sais, açúcar e outras substâncias provocam a redução do valor de Aw de um alimento pela saturação, com a redução o valor da pressão parcial de vapor da água contida na solução ou no alimento (FRANCO e LANDGRAF, 1996).

\section{Compostos fenólicos}

Os teores de fenólicos totais foram afetados pelas diferentes concentrações do biofilme entre os tratamentos e durante o período de armazenamento $(\mathrm{p} \leq 0,05)$, confirmada pelo teste de Tukey. 
Figura 2 - Evolução do teor de compostos fenólicos totais em tomate cv. Rasteiro coberto com biofilme de diferentes concentrações de óleo essenciais, durante o período de armazenamento

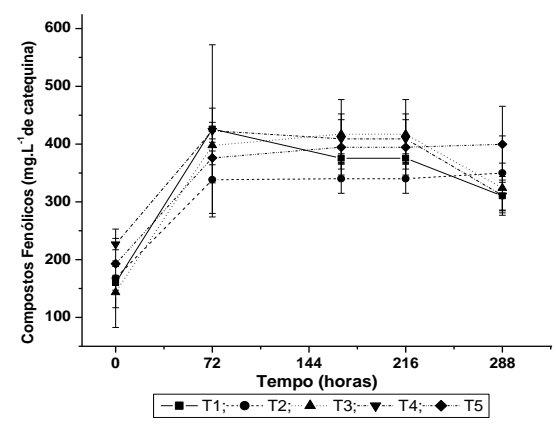

As concentrações iniciais dos compostos fenólicos variaram de 143,19 a $193,04 \mathrm{mg} \mathrm{L}^{-1}$ de catequina entre os tratamentos. O conteúdo de fitoquímicos nos frutos pode ser afetado pelo grau de maturação e condições ambientais durante a colheita, por diferenças genéticas entre cultivares, pela manipulação dos frutos e por condições de estocagem pós-colheita (CHITARRA e CHITARRA, 2005).

Durante o período de armazenamento todos os tratamentos tiveram aumento nos valores dos compostos fenólicos totais até $216 \mathrm{~h}$, com declínio posterior. Os aumentos entre os tratamentos 1, 2, 3, 4 e 5 foram de 94,0\%, 108,6\%,126,3\%, 37,1\% e 107,0\%, repectivamente. O aumento pode ser explicado pela indução da biossíntese dos compostos fenólicos com o intuito de formar defesa contra o estresse causado no processamento que foram submetidos os tomates, além do ataque de microrganismos, já que não houve outra cobertura durante o armazenamento. Segundo Moretti (2007) as primeiras respostas fisiológicas ao estresse, causado pelo processamento mínimo no vegetal, são os aumentos transientes na evolução do etileno e elevação na atividade respiratória, que podem estar interligados com a indução do metabolismo dos compostos fenólicos e com o processo de cicatrização do tecido. Segundo Aditivos e Ingredientes (2011) os óleos essenciais adicionados ao biofilme também podem ter contribuído para acentuar a concentração de compostos fenólicos, já que está relacionada a atividade antioxidante encontrada na sálvia como a presença de ácido carnósico, carnosol e ácido rosmarínico. A manjerona apresenta como principal substância antioxidante os flavonóides. Porém, a redução após $216 \mathrm{~h}$ pode ser decorrente da intensa oxidação dos compostos fenólicos, acarretando escurecimento nos frutos, causada por alterações metabólicas ou de reações de condensação enzimática ou não enzimática (Figura 2).

\section{Conclusão}

Os tomates cobertos com biofilmes com adição da combinação de sálvia e manjerona, mostraram maior eficiência na atividade antimicrobiana, e na manutenção da concentração dos 
compostos fenólicos, promovendo aumento da vida de prateleira desses frutos, ao serem armazenados em temperatura ambiente.

\begin{abstract}
The purpose of this paper was evaluate the application of biofilm with essential oils, with microbial activity, for the conservation after harvest of tomato $c v$ Rasteiro. The tomatoes were covered with biofilm, having as composition the potato starch and glycerol, in the proportions of 2,5\% and 0,7\%, respectively, and the addition of 0,5\% of essential oils of sage and marjoram, according to the factorial experimental planning $2^{2}$, stored in room temperature during $288 \mathrm{~h}$. The tomatoes with biofilm added of essential oils showed microbial count in the acceptable limit of $10^{6} \mathrm{UFC} / \mathrm{g}$ until 168h. The water activity didn't show significant variation during the storage period. All the treatments (1, 2, 3, 4 and 5) had increasing 94,0\%, 108,6\%, 126,3\%, 37,1\% and 107,0\%, respectively, in the values of total phenolic compounds until 216h. The tomatoes covert with biofilms with addition of sage and marjoram combination showed higher efficiency in the antimicrobial activity and in the maintenance of the concentration of the phenolic compounds, promoting increase in the shelf life when storage in room temperature.
\end{abstract}

Key-Words: Biofilm, essential oils, tomato, antimicrobial activity.

\title{
Referências
}

ADITIVOS \& INGREDIENTES . Antioxidantes vegetais, frutas, ervas, especiarias e chás. Disponível em: <http://www.insumos.com.br/aditivos_e_ingredientes/materias/129.pdf> Acesso em: 05/05/2011.

ALMEIDA, Denise Milleo. Biofilme de blenda de fécula de batata e celulose bacteriana na conservação de fruta minimamente processada. 2010. 283f. Tese (Doutorado em Processos Biotecnológicos) Universidade Federal do Paraná, Curitiba-PR.

ASSIS, O. B. G.; FORATO, L. A.; BRITTO, de. Revestimentos comestíveis protetores em frutos minimamente processados. Higiene Alimentar, v. 22, n. 160, p. 99-106, 2008.

BENDER, R. J.; PEZZI, E.; LEÃO, M. L.; CASALI, M. E. Armazenagem de morangos cv. Camarosa e cv. Verão em atmosfera modificada. Acta Scientiarum Agronomy, v. 32, n. 2, p.285-292, 2010.

BEUCHAT, L.R.; GOLDEN, D. A. Antimicrobials occurring naturally in foods. Food Technology, v. 43, p. 134-142, 1989.

BOLZAN, R. P. Biofilmes comestíveis para conservação pós-colheita de tomate 'Dominador'. $2008.167 \mathrm{f}$. Dissertação (Mestrado em Agronomia) Universidade Federal do Paraná, Curitiba, 2008.

BUSATTA, C., VIDAL, R. S., POPIOLSKI, A. S., MOSSI, A. J., DARIVA, C., RODRIGUES, M. R. A. Application of Origanum majorana L. essential oil as antimicrobial agent in sausage. Food Microbiology, v. 25, p. 207-211, 2008. DOI: $10.1016 /$ j.fm.2007.07.003

CHITARRA, M.I.F.; CHITARRA, A.B. Pós-colheita de frutas e hortaliças: fisiologia e manuseio. 2nd, Lavras: UFLA, 785 p., 2005.

DAVIDSON, P. M.; NAIDU, A. S. Phyto-phenol. In: Naidu, AS.(Ed.) Natural Food Antimicrobial Systems. CRC Press, Boca Raton, FL, p. 265-294, 2000.

FRANCO, B. D. G. M.; LANDGRAF, M. Microbiologia dos alimentos. São Paulo, Atheneu, 181 p. 1996.

FOOD INGREDIENTS BRASIL. Agentes antimicrobianos químicos e naturais. Disponível em: http://www.revistafi.com/materias/155.pdf Acesso em 05/05/2011. 
KESTER, J. J.; FENNEMA, O. R. Edible films and coatings: a review. Food Technology, v. 40, n. 12, p. 47-59, 1986.

LAMBERT R. J. W.; SKANDAMIS P. N.; COOTE P. J.; NYCHAS G.-J. E. A study of the minimum inhibitory concentration and mode of action of oregano essential oil, thymol and carvacrol. Journal of Applied Microbiology, v. 91 p.453-462, 2001. DOI:10.1046/j.1365-2672.2001.01428.x

MORETTI, C. L. Laboratório pós-colheita, Embrapa Hortaliças. 2007 Disponível em http:< www.cnph.embrapa.br/public/textos/texto7.html>. Acesso em: 11 junho de 2010.

PEREIRA, R. S; SUMITA, T. C; FURLAN, M. R; JORGE, A. O. C; UENO, M. Atividade bacteriana de óleos essenciais em cepas isoladas de infecção urinária. Revista de Saúde Pública, v. 38, p. 326-328, 2008. DOI: $10.1590 / \mathrm{S} 0034-89102004000200025$

SILVA, N.; JUNQUEIRA, V. C. A.; SILVEIRA, N. F. A. Manual de métodos de análise microbiológica de alimentos. São Paulo, Varella, 295 p., 2010.

SINGH, A.; SINGH, R. K; BHUNIA, A. K.; SINGH, N. Efficacy of plant essential oils as antimicrobial agents against Listeria monocytogenes in Hotges. Lebensmittle Wissenchet und Technologie (LWT), v.36, p. 787-794, 2003. DOI: 10.1016/S0023-6438(03)00112-9

SINGLETON, V. L.; ROSSI J. R, J. A. . Colorimetry of total phenolics with phosphomolybdic-phosphotungstic acid reagents. American Journal of Enology and Viticulture, v. 16, p. 144-158, 1965.

SOUZA, E. L. Potencial antimicrobiano do óleo essencial do orégano (Origanum vulgare L.): uma abordagem para o uso em sistemas de conservação de alimentos. Tese (Doutorado em Nutrição). Programa de Pós-Graduação em Nutrição, Universidade Federal de Pernambuco. Recife-PE. 2006.

VIEITES, R. L.; EVANGELISTA, R. M.; CAMPOS, A. J.; MOREIRA, G. C. Avaliação da contaminação microbiana do mamão minimamente processado e irradiado. Revista Higiene Alimentar, v. 18, n .118, p.65-68, 2004.

Trabalho selecionado para apresentação oral durante a VIII SETAL- Semana de Tecnologia de Alimentos- Câmpus Ponta Grossa- Universidade Tecnológica Federal do Paraná- 01 a 03 de junho de 2011. Suplemento especial da RBTA. 